\title{
Breve história da arqueologia bíblica: contribuição e crítica estadunidense
}

\author{
Brief history of biblical archeology: contribution and \\ american criticism
}

\section{Breve historia de la arqueología bíblica: contribución y crítica estadounidense}

\author{
Fábio Augusto Darius* \\ Elder Hosokawa**
}

\begin{abstract}
RESUMO
A arqueologia bíblica, ramo da arqueologia que se dispõe a estudar as evidências materiais relacionadas de forma direta ou indireta a partir de relatos bíblicos ou evidenciados no texto das Escrituras judaico-cristãs, tem sua origem com o nascimento da própria arqueologia. Suas técnicas, inclusive, são as mesmas. Seu escopo não é o de objetivamente comprovar a fé ou desvelar supostos erros cometidos pelos autores dos textos bíblicos, mas tão somente instrumentalizar o estudante da Bíblia e/ou da arqueologia em geral para que melhor se compreenda e visualize os textos históricos. O objetivo do presente trabalho é, de forma incipiente, relacionar os principais nomes e acontecimentos deste ramo da arqueologia desde suas origens, ainda no século 19 até o presente, a partir da história da arqueologia tradicional, e apresentar a contribuição estadunidense para pesquisa, divulgação e crítica à arqueologia bíblica.

Palavras-chave: Arqueologia Bíblica; Oriente Próximo; Arqueologia Siro-Palestina; História Contemporânea
\end{abstract}

\begin{abstract}
Biblical archeology, a branch of archaeology that is willing to study material evidences related directly or indirectly from Biblical accounts or related to the text of the Judeo-Christian Scriptures has its origin with the birth of archeology itself. Their techniques are the same. Its objective is not to objectively prove the faith or to reveal supposed errors made by the authors of the biblical texts, but only to equip the student of the Bible and / or Archeology in general to better understand and visualize historical texts. The aim of the present work is, in an incipient way, to relate the main names and events of this Archeology branch from its origins, still in the nineteenth century to the present, from the history of traditional archeology and present the American contribution for research and dissemination and criticism to Biblical Archeology.
\end{abstract}

Keywords: Biblical Archaeology; Near Eastern; Syro-PalestinianArchaeology; Contemporary History.

* Centro Universitário Adventista de São Paulo - UNASP, campus Engenheiro Coelho. Doutor e Mestre em Teologia Histórica pela Escola Superior de Teologia (EST) em São Leopoldo, RS. Historiador pela Universidade Regional de Blumenau (FURB), SC. Docente no Centro Universitário Adventista de São Paulo (UNASP) campus Engenheiro Coelho. fabio.darius@unasp.edu.br .

** Centro Universitário Adventista de São Paulo - UNASP, campus Engenheiro Coelho. Mestre em História Social, Bacharel e Licenciado em História pela Universidade de São Paulo (USP) em São Paulo, SP. Docente do Centro Universitário Adventista de São Paulo (UNASP) campus Engenheiro Coelho. elder.hosokawa@unasp.edu.br. 


\begin{abstract}
RESUMEN
La arqueología bíblica, rama de la arqueología que se dispone a estudiar las evidencias materiales relacionadas de forma directa o indirecta a partir de relatos bíblicos o relacionados al texto de las Escrituras judeo-cristianas tiene su origen con el nacimiento de la propia arqueología. Sus técnicas, incluso, son las mismas. Su alcance no es el de objetivamente comprobar la fe o desvelar supuestos errores cometidos por los autores de los textos bíblicos, sino tan sólo instrumentalizar al estudiante de la Biblia y / o de la arqueología en general para que mejor se comprenda y visualice los textos históricos. El objetivo del presente trabajo es, de forma incipiente, relacionar los principales nombres y acontecimientos de esta rama arqueología desde sus orígenes, aún en el siglo XIX hasta el presente, a partir de la historia de la arqueología tradicional y presentar la contribución estadounidense para investigación y divulgación y crítica a la arqueología bíblica.

Palabras clave: Arqueología Bíblica; Oriente Próximo; Arqueología Siro-Palestina; Historia Contemporánea
\end{abstract}

\title{
Conceito e contexto histórico da Arqueologia em breves linhas
}

A arqueologia, que pode ser percebida genericamente como uma espécie de estudo das atividades humanas no passado, diz respeito à análise da cultura material a partir de achados arqueológicos, geralmente a partir de indicações diretas ou indiretas de textos clássicos ou outras evidências. Os mais diversos artefatos e percepções arquitetônicas, bem como os chamados biofatos - como, por exemplo, madeira, celulose ou carboidrato - podem culminar com um achado de grande relevância para a Humanidade, desvendando pontos civilizacionais que ajudam a melhor compreensão de certas lacunas do passado e do presente. Produto da modernidade e interdisciplinar desde seus inícios ${ }^{1}$, a arqueologia está em constante evolução e, para o bem ou para o mal, muitas vezes ligada a certos interesses que escapam de seu escopo. De acordo com João Carlos Moreno de Sousa, a arqueologia

\begin{abstract}
é a ciência que estuda vestígios materiais da presença humana, sejam estes vestígios antigos ou recentes, com o objetivo de compreender mais sobre os mais diversos aspectos da humanidade. Pode-se dizer que o arqueólogo é o detetive que tem a obrigação de investigar os mais diversos tipos de vestígios materiais para compreender o contexto de atividades humanas em um determinado tempo e espaço. Para este tipo de trabalho, o arqueólogo deve ser um bom conhecedor das ciências humanas, das ciências biológicas, das ciências da terra, e até das ciências exatas. O arqueólogo é, talvez, o cientista mais interdisciplinar e multidisciplinar que se pode encontrar (SOUSA, 2015, [texto publicado em mídia digital, sem paginação]).
\end{abstract}

O arqueólogo brasileiro Pedro Paulo Funari (1988, p. 11), também conceituando o termo, refere-se à arqueologia como "a totalidade material

Pedro Paulo Funari, já em escrito de 1988, referenciado ao final deste artigo, escrevia que há "preocupação crescente com a interdisciplinaridade, buscando-se um intercâmbio, quanto ao modo de leitura, com campos de atuação paralelos e complementares. Isto é particularmente válido no que diz respeito à Semiótica, preocupada com os princípios teóricos da comunicação - e, portanto, com a leitura em geral -, mas atinge já outros tipos de leitura, aparentemente distantes da Arqueologia, como a Psicanálise" (FUNARI, 1988, p. 22) 
e imaterial apropriada pelas sociedades humanas como parte de uma cultura total, material e imaterial", enquanto Renfrew e Bahn (2007, p. 10) afirmam que "a arqueologia é tanto uma ciência como uma disciplina humanística", reafirmando sua dependência interdisciplinar.

Em virtude de sua grande exigência preparatória e os altos custos empreendidos, apenas poucos países podem efetivamente dispor de escolas preparatórias com estudos consistentes, além de custear as próprias escavações. No Brasil, a arqueologia ainda é "percebida como uma disciplina auxiliar" (FUNARI, 1994, p.24).

Embora oficialmente iniciada enquanto ciência no século 19, já desde o quinto século antes de Cristo há evidências de sistematização. Heródoto, por exemplo, talvez tenha sido o primeiro ocidental a recolher artefatos para verificações posteriores, além de ser o primeiro a fazer uma narrativa do passado. Possivelmente também explorou o Nilo e Delphi.

No Renascimento, Ciríaco de Ancona, humanista italiano, anotou suas descobertas arqueológicas de forma precisa em seis volumes e é, certamente, um dos pais da Arqueologia, precisamente no contexto da mudança paradigmática da passagem do Medievo para a Modernidade. Destacam-se, ainda, Flávio Biondo e os posteriores antiquários, como Sir. Richard Colt Hoare, coletor e exibidor de artefatos, em seus primeiros passos experimentais para a sistematização da Arqueologia.

$\mathrm{Na}$ Idade Moderna, Christian J. Thomsem foi o primeiro a dividir a pré-história em três distintos períodos, os clássicos Idade da Pedra, Bronze e Ferro. Sir Robert Eric Mortimer Wheeler (1890-1976) criou o método estratigráfico para escavações e estudo de sítios arqueológicos.

Pretende-se, com essa breve introdução, ajudar a perceber que a arqueologia bíblica não nasceu em um vácuo, talvez tão somente por conta de um novo ou renovado interesse pela Bíblia no mundo ocidental. Todos os desafios, percalços e avanços anteriores serviram para que a arqueologia bíblica fosse encontrando seu próprio espaço ao longo das décadas após seu nascimento.

\section{A arqueologia bíblica e o silêncio da arqueologia}

O nacionalismo nascente no século 19 serviu como grande fomentador da arqueologia ${ }^{2}$. Era importante, além da demonstração de força, a percepção de superioridade racional, em um momento histórico em que Charles Darwin lançava as bases de sua famosa teoria acerca da seleção natural. Nesse sentido,

Ainda de acordo com Funari, a arqueologia surgiu "no auge do nacionalismo e do imperialismo, como parte da conquista militar e espiritual do mundo" (FUNARI, 2013, p. 23). 
uma comprovação empírica dessa superioridade, através de uma escavação, poderia ajudar na escrita dos mitos fundantes de determinada nação e dar novo significado à própria ideia de nação.

Nesse contexto preciso, ainda no final do século 18, como é relativamente bem conhecido, um engenheiro que trabalhava para Napoleão Bonaparte encontrou a famosa Pedra de Rosetta, na cidade homônima, no Egito, "próximo da desembocadura do braço ocidental do Nilo" (OWEN, 2002, p.1503). Ainda de acordo com Owen, "esta pedra era um pilar de granito negro, ovalado na parte superior, de uma laje de 114 centímetros de altura, 71 de largura e 28 de espessura" (2002, p.1503). Quase 25 anos depois da descoberta do famoso pilar, Champollion, em 1822, publicou as traduções completas do conteúdo. A pedra foi um grande marco arqueológico e serviu como ponto de inflexão para que a arqueologia pouco a pouco mostrasse sua pujança e interesse renovados.

Note-se que a arqueologia bíblica nasce nesse contexto específico. Não há metodologia distinta para supri-la ou tampouco técnica específica que não sirva também para a arqueologia como um todo. Contudo, deve-se frisar, no tocante à arqueologia bíblica, os mesmos perigos de usos e propósitos da arqueologia geral, aqui já comentados: enquanto o nacionalismo foi o grande mote para incursões arqueológicas, a arqueologia bíblica, por vezes, se arvorara como a ciência que, por fim, "comprovará empiricamente a verdade bíblica", subjugando a fé necessária ao crente a um incômodo segundo plano. Simplesmente, a arqueologia bíblica pode hoje ser usada a favor ou contra a Bíblia. Em 1955, o jornalista Werner Keller escreveu o clássico E a Bíblia tinha razão, que serviu de mote a muitos pastores e teólogos não iniciados, utilizando a obra como evidência arqueológica da existência factual de uma infinidade de sítios bíblicos. Em 2003, chega ao Brasil a obra antitética de Keller, precisamente chamada E a Bíblia não tinha razão, escrita pelo famoso arqueólogo israelense Israel Finkesltein com a colaboração de Neil Asher Silberman, contestando o texto de Keller. A obra objetiva, dentre outras pretensões, minimizar o ufanismo de certos escritores, que se utilizam da arqueologia como instrumento de demonstração da literalidade do texto bíblico, geralmente para fins evangelísticos ${ }^{3}$. O simples exemplo ora apre-

\footnotetext{
Numerosos sites apresentam essas descobertas e capitalizam as descobertas para fins evangelísticos. Pensar na arqueologia bíblica com esse fim, no entanto, não extingue seus outros diversos propósitos. O texto a seguir é apenas um dos muitos encontrados acerca do uso da arqueologia bíblica como mote cristão: "Escavações entre 1969 e 1976 têm revelado enormes paredes, portões, poços e depósitos consistentes com os relatos bíblicos. A cidade antiga de Jerusalém, que remonta à época da conquista inicial do rei Davi, foi descoberta e escavada entre 1978 e 1985. Antes dessa época, não havia nenhuma outra fonte extrabíblica sobre a Jerusalém do Rei Davi, a qual desde então tem revelado um palácio,
} 
sentado estabelece que existe um grande uso e abuso da Arqueologia com pretensão ideológica, ou, no mínimo, mercadológica, impedindo que a arqueologia mesma fale por si. Por conta disso, é possível apresentar, sem alegar qualquer pretensão foucaultiana, o silêncio da arqueologia: quando a mesma não defende aludido ponto de vista, é simplesmente rechaçada, novamente atestando seu uso ideológico.

Para muito além dessa discussão, é perceptível que a Bíblia acabou por se tornar "o centro da vida intelectual e religiosa do mundo ocidental" precisamente nos anos 1800 (MOOREY, 1991, p.1). Ao longo de boa parte do século 19, bem como dos anteriores, pinturas e esculturas foram criadas com temas bíblicos e a imaginação de cronistas acerca de descrições e epopeias bíblicas pode ser largamente atestada, com ou sem o devido fundamento histórico-social.

Foi apenas nos anos 1890, quando da escavação de Tell el-Hesi, na Palestina, que foram reveladas duas civilizações distintas, uma no Egito e outra na Mesopotâmia. Suas inscrições não apenas puderam ser desenterradas, mas também lidas, mudando grandemente a percepção ocidental do mundo bíblico, ainda que com as ressalvas ideológicas acima apresentadas.

O interesse pelo "falar das pedras", no entanto, se deu pelo racionalismo inerente ao século 19, que presenciou o nascimento do darwinismo e desenvolvimentos em quase todas as áreas das ciências, com especial ênfase na biologia. Portanto, a arqueologia bíblica não nasce no vácuo, mas, sim, enquanto paradigma gestado e muito desejado, ainda que contrapontual. Afinal, a técnica e a tecnologia seriam utilizadas para fomentar o transcendente. A lógica seria utilizada para instrumentalizar e subsidiar a fé. É importante distinguir os dois escopos:

Seu alcance [diz respeito] como Arqueologia, não Teologia; mas a teologia será uma ajuda importante. Para todos aqueles, deve ser atraente a quem está interessado na história primitiva e antiga da humanidade; aquela história que não está escrita em livros nem

torres e a famosa fonte de Siloé (2 Samuel e 1 Crônicas). As ruínas antigas de Gibeá foram descobertas cerca de três quilômetros ao norte de Jerusalém. Gibeá foi a morada de Saul e da tribo de Benjamim, e mais tarde tornou-se a cidade capital do rei Saul (Juízes 19 e 1 Samuel 10-15). As escavações têm revelado o palácio-fortaleza de Saul de cerca de 1100 aC. Megido era uma cidade cananeia conquistada por Israel, no norte. Era uma fortaleza murada que se localizava em uma colina perto de uma extensa planície que testemunhou muitas batalhas de significado histórico. No século 10 a.C, o Rei Salomão fortificou a cidade (1 Reis 4:12) e mais tarde, no século 7 a.C, o rei Josias perdeu uma batalha para os egípcios lá. De acordo com Apocalipse 16,16, Megido (também conhecida como Armagedom) é o local da batalha final mundial, onde Jesus Cristo vai derrotar as forças de Satanás e estabelecer o Seu reino glorioso de todos os tempos" https://www.allaboutarchaeology.org/portuguese/arqueologia-biblica. htm. Último acesso em 3 nov 2017. Chama a atenção, talvez, mais o nome do site que propriamente o conteúdo aqui destacado: “Tudo sobre arqueologia”(!). 
em papel, mas em pedras e rochas, no fundo do solo, muito longe no deserto; aquela história que não se encontra na biblioteca ou no mercado deve ser desenterrada no vale do Nilo ou exumada das planícies da Mesopotâmia (BIRCH apud MOOREY, 1991, p.3).

A afirmação acima, romantizada e assim percebida na própria época da escrita, embora não diga o que a arqueologia bíblica seja, fornece algumas indicações. Objetivamente, arqueologia bíblica pretende estudar meticulosa e metodologicamente descobertas relacionadas aos relatos bíblicos. A fé continuará sendo outra prerrogativa, pertencendo a outro campo, não necessariamente integrante ao arqueólogo de um sítio elencado ao contexto bíblico.

\section{Nomenclaturas em disputas nos Estados Unidos}

William Foxwell Albright e Nelson Glueck, dois arqueólogos norte-americanos, se notabilizaram como representantes da escola de pensamento conservador que aproximaram a Bíblia com os achados arqueológicos do século 20 no Oriente Próximo.

É consenso considerar William Foxwell Albright (1891-1971) decano da arqueologia bíblica nos Estados Unidos por sua sólida formação acadêmica, pelas escavações que participou, pelo impacto que exerceu na mídia, por suas relações de amizade com os dirigentes do nascente Estado de Israel. Seu livros e artigos impactaram o mundo cristão nos Estados Unidos e também ao redor do planeta. Suas palestras arrecadaram fundos para escavações e a criação de um centro de pesquisas arqueológicas em Jerusalém (FREEDMAN, D. N.; RUNNING, 1991).

Colaborando com agências protestantes estadunidenses e israelenses, Albright defendia a historicidade dos personagens e eventos bíblicos e afirmou que:

O leitor pode ter certeza de que nada foi encontrado para perturbar uma fé razoável, e nada foi descoberto que pode refutar uma única doutrina teológica. Nós já não nos preocupamos com tentativas de harmonizar a religião e a ciência, ou a provar a Bíblia. A Bíblia pode se sustentar por si mesma. Contudo, não existe a menor dúvida de que a arqueologia tem confirmado substancialmente a historicidade fundamental da tradição do Antigo Testamento (Albright, 1956, p.176).

Filho de missionários metodistas no Chile, Albright estudou nos Estados Unidos e doutorou-se em 1916, na John Hopkins University e ali atuou como pesquisador e professor entre 1929 e 1959, sendo diretor da American School of Oriental Research na mesma universidade. Contribuiu para confirmação da autenticidade dos manuscritos do Mar Morto, após seus achados em 1947. 
Segundo Shanks (1992, p.150) Albright foi “o mais notável arqueólogo especialista em Oriente Próximo, epigrafista hebraico da sua geração, imediatamente saudou o achado como a maior descoberta de manuscritos dos tempos modernos".

Albright, desde 1923, já vinha escavando nas imediações de Jerusalém. Entre 1926 e 1932, ele se dedicou ao trabalho de campo no Tall Beit Mirsim, nas proximidades de Hebron. Albright, seus alunos e colaboradores iniciaram um movimento de inclusão e envolvimento crescente dos Estados Unidos em escavações que coincidiu com a expansão da influência norte-americana no mundo, em contraposição ao colapso do imperialismo inglês no Egito e Oriente Médio.

Deve ser lembrada a contribuição de George Ernest Wright (19091974) que estudou com Albright na John Hopkins University, onde doutorou-se em 1937. Foi professor da Harvard Divinity School, em 1958, colaborador e membro do Museu Semítico de Harvard até sua morte. Especialista em estudos do Antigo Testamento e arqueologia bíblica, escavou com Albright e deu importante contribuição ao debate teológico como especialista em arqueologia do Oriente Próximo. Numa avaliação crítica produzida por Davis (2004, p.95)

Wright produziu uma mudança crucial no paradigma da arqueologia bíblica. Ele tomou a construção "científica" do campo e deu uma existência racional positiva. Deu à arqueologia bíblica um suporte estrutural para uma compreensão teológica positivista conhecida como Movimento Bíblico Teológico.

O professor George Ernest Wright fundou a revista Near Eastern Archaeology Magazine. Nos estudos da Palestina dentro da arqueologia bíblica, o manto de Elias foi passado de Albright para Wright.

As narrativas sobre arqueologia indicam duas fases na trajetória de pesquisas nesse campo. Até a Segunda Grande Guerra predominaram a Inglaterra, a Alemanha, a Áustria e a França, com crescente participação e protagonismo norte-americano. Após a Segunda Grande Guerra, aumentou o interesse pelo tema, e a arqueologia bíblica tornou-se um campo de pesquisa. Funari e Rodrigues (2009, p.9) afirmaram que:

[...] no período entre guerras, as pesquisas norte-americanas começaram a dominar o cenário. O destaque ficou para William Foxwell Albright, que, na década de 1920, tornou-se presidente da ASOR e entusiasta de suas campanhas. Hoje, Albright, apesar de não ser arqueólogo de formação, é considerado o "padrinho" da disciplina nos Estados Unidos, graças a suas contribuições metodológicas e epistemológicas. 
Reconhecido em Israel e nos Estados Unidos por suas pesquisas e escavações arqueológicas no deserto do Neguev, o rabino Nelson Glueck (19001971) destacou-se por uma de suas citações sobre a arqueologia e a Bíblia:

De fato, pode-se declarar afirmativamente que nenhuma descoberta arqueológica jamais contradisse uma referência bíblica. As indicações que os achados arqueológicos têm feito confirmam, em linhas gerais óbvias ou em detalhes precisos, as afirmações históricas da Bíblia. E, como prova do que afirmo, a avaliação adequada das descrições bíblicas frequentemente leva a descobertas impactantes. Formam as peças do amplo mosaico da memória histórica quase inacreditavelmente correta da Bíblia (GLUECK, 1959, p. 31).

Glueck era filho de judeus alemães e doutorou-se na Alemanha na Universidade de Jena, em 1926. Tornou-se professor do Hebrew Union College, em 1928, ensinando no seminário do movimento judaico de reforma. Especialista em cerâmica antiga, por mais de 40 anos escavou em busca de sítios arqueológicos, usando a Bíblia como seu guia. Sua mais importante descoberta veio em 1934, quando identificou as minas do rei Salomão em Khirbet Nahas. Mais tarde, identificou Ezion Geber no Mar Morto como possível localização do porto e fortaleza do rei Salomão. No obituário de Glueck no The New York Times (1971, p.75) foi mencionado que, em 1967, o ex-aluno de Albright foi saudado pelo professor como "herói da arqueologia bíblica".

As mortes de Albright e Glueck, ambas em 1971, encerraram o período áureo da arqueologia bíblica nos Estados Unidos e o que veio a seguir foi marcado por muita disputa no vácuo deixado por esses ícones. Nos anos 1970, o debate entre a academia e grupos fundamentalistas nos Estados Unidos sobre o uso da arqueologia para o embasamento de eventos bíblicos deu espaço para uma reflexão mais consolidada (BURKE, 2010, p. 1).

William G. Dever participou desse embate que arrastou teólogos, arqueólogos na busca de conexões e redefinições nas questões de fé e o diálogo com os pesquisadores de vanguarda da comunidade arqueológica (SOTELO, 2003).

Na arqueologia, a expressão "bíblica”, em 1974, começou a disputar com um novo adjetivo "siro-palestino", um termo geográfico que trouxe a discussão para uma perspectiva pós-moderna de tolerância no embate de ideias ainda em conflito (KLINGBEIL, 2002). Mas, 21 anos depois, o quadro se alterou:

Dever proclamou a morte da arqueologia bíblica e siro-palestina na América do Norte (1995). Mencionou os crescentes custos dos trabalhos de campo, o corte de verbas de agências de financiamento, a redução de apoio para as humanidades, a perda do apoio de recursos oriundo de igrejas e a emergência de escolas nacionais de arqueologia, a política para o Oriente Médio como as causas dessa crise. 
William G. Dever (2006, p.26) escreveu sobre o legado de Albright, nos Estados Unidos, e a consolidação de sua reputação:

Já faz uma geração que os arqueólogos bíblicos falam com confiança da revolução arqueológica de William F. Albright. Esta seguramente realizaria nossa compreensão e apreciação da Bíblia e sua mensagem atemporal - a qual foi pensada para ser absolutamente essencial a nossa querida condição cultural ocidental. A Bíblia e a "cultura ocidental" como foram concebidas anteriormente, lutam por suas vidas. A arqueologia moderna não só pode ajudar a confirmar a tradição antiga, mas, pelo que parece, também trata de miná-la. Este é um segredo, bem guardado, dos arqueólogos profissionais. A revolução arqueológica, em sua moderna crítica, tem como objetivo trabalhar tanto o extremo cepticismo como a ingênua credulidade. Não se pode voltar ao tempo no qual a arqueologia presumia provar a Bíblia. A arqueologia, como se pratica na atualidade, deve ter a capacidade de desafiar, e confirmar, os relatos bíblicos [...]. Na verdade, a arqueologia não pode explicar o significado dos supostos eventos descritos na Bíblia. Essa é uma decisão inteiramente pessoal. A arqueologia não pode responder a esta pergunta. Esta só pode dar sua visão.

Dever é percebido como uma referência na moderna arqueologia siro-palestina. As disputas acadêmicas não cessaram diante de grupos tão antagonizados na segunda metade do século 20, após as descobertas de Qumran. Em 1947, o fascínio por Israel atraiu crentes de todos os cantos do mundo, incluindo pesquisadores que viam oportunidade de aprofundar sua compreensão sobre o passado. A controvérsia nos Estados Unidos, embasada em pressuposições filosóficas que extrapolaram a nomenclatura siro-palestina, revela o desafio nessa área do conhecimento.

J. Randall Price (2006, p.263) arqueólogo protestante norte-americano, autor e produtor de livros e documentários, sintetizou os dois grupos que surgiram na segunda metade do século 20 e que avançaram o século seguinte com embates de alta ignição, referindo-se aos minimalistas e maximalistas;

[...] os minimalistas bíblicos (os que limitam a historicidade das narrativas bíblicas) consideram os maximalistas bíblicos (os que não limitam a historicidade das narrativas bíblicas) faltos de objetividade e profissionalismo. Os minimalistas até preferem descartar o termo arqueologia bíblica e substituí-lo por um termo como arqueologia siro-palestina. A intenção desta mudança é retirar da arqueologia a identificação com a Bíblia e tratá-la tão-somente como um ramo regional da arqueologia em geral.

As disputas interpretativas entre maximalistas e minimalistas em Israel, envolveram a tradicional e conservadora Universidade Hebraica de Jerusalém e os arqueólogos minimalistas da Universidade de Tel Aviv. A participação dos Estados Unidos se reduziu e a atenção se volta para Israel. 
Parte das pesquisas arqueológicas em Israel foi financiada ou teve o apoio direto do Estado. Segundo Kaefer (2015, p.14), isto fez com que as pesquisas defendessem os interesses do Estado. Os judeus empenhados na consolidação econômica, política, cultural e ideológica do Estado de Israel, ainda lutam pela manutenção de suas fronteiras num contexto de franca hostilidade com palestinos e árabes, que disputam territórios com milênios de história por surpreender pesquisadores de ambas as trincheiras.

As pesquisas ainda buscam colaboração internacional cada vez mais escassa entre instituições norte-americanas. Novos métodos estão se aperfeiçoando, destacando-se o uso da estratigrafia nas escavações arqueológicas (RODRIGUES; FUNARI, 2009, p. 100).

Os judeus aparentam respeitar os grupos evangélicos messiânicos e fundamentalistas, levando adiante o legado, por vezes fora de moda, da arqueologia bíblica como delineado por Albright, Glueck e Wright. Evangélicos fundamentalistas nos Estados Unidos, América Latina, Ásia podem ser novos atores nesse cenário, que está longe de perder o seu vigor.

\section{Conclusões}

A arqueologia bíblica, incipientemente aqui historicizada, de forma indelével se mostra poderosa ferramenta ao estudante da Bíblia. O número de comentários bíblicos escritos ou atualizados a partir das novas descobertas arqueológicas, bem como a publicação de bíblias de estudo, incluindo edições inteiras destinadas à arqueologia, sem contar o sem número de softwares livres ou pagos contendo mapas atualizados e inscrições arqueológicas apenas prova o ponto. Contudo, a arqueologia bíblica deve servir para mais do que isso: a ciência arqueológica brinda a humanidade com a própria possibilidade de sua autodescoberta. Transcende, portanto, a geografia bíblica e a nova ou melhor interpretação de textos de interesse de judeus e cristãos, prioritariamente. Contudo, a arqueologia bíblica precisamente contribui para que se aumente o escopo do conhecimento humano. Nesse sentido, a arqueologia bíblica beneficia a sociedade inteira, não apenas aquela fração, ainda que muito significativa, dos crentes.

Conhecer a arqueologia bíblica e perceber sua dimensão para além dos textos sagrados é, portanto, interesse de todo aquele que se alegra e, simultaneamente, se preocupa com a sua condição humana. Afinal, a arqueologia bíblica tão somente demonstra a breve passagem de povos distintos, bem como suas contribuições e dificuldades, humanizando e melhor caracterizando homens e mulheres de outros tempos.

Aquilo que outrora foi percebido por nomes de peso como Albright, Glueck e Wright, contando com a colaboração de pesquisadores contemporâneos, atesta a inegável riqueza cultural do texto e contexto bíblicos, 
precisamente por apresentar os povos tais como eles são. Ao contrário do conhecido dito que afirma que "o papel aceita tudo", as pedras não mentem.

\section{Referências bibliográficas}

ALBRIGHT, W.F. Archaeology and the religion of Israel. Baltimore: The Johns Hopkins Press, 1956.

BIRCH, S. The progress of biblical archaeology: an address. Transactions of the Society of Biblical Archaeology. Vol. I. London: Society of Biblical Archaeology, 1872.

BURKE, A.A. The archaeology of the Levant in North America: the transformation of biblical and syro-palestinian archaeology. In. LEVY, Thomas E. (Ed.) Historical biblical archaeology and the future: the new pragmatism. New York: Routledge Park, 2010.

DAVIS, Thomas.Shifting sands: the rise and fall of biblical archaeology. New York: Oxford University Press, 2004.

DEVER, W.G. The western cultural tradition is at risk. Biblical Archaeology Review, vol. 32, n. 2, p. 26-76, march/apr. 2006.

FREEDMAN, D.N.; RUNNING, L.G. (Ed.) William Foxwell Albright. a twentieth-century genius. Berrien Springs: Andrews University Press, 1991.

FUNARI, P.P.A. Arqueologia. São Paulo: Ática 1988.

FUNARI, P.P.A. Arqueologia brasileira: visão geral e reavaliação. Disponível em http://www. unicamp.br/chaa/rhaa/downloads/Revista\%201\%20-\%20artigo\%202.pdf

FUNARI, P.P.A. Arqueologia no Brasil e no mundo: origens, problemáticas e tendências. Ciência e Cultura, vol. 65, p. 23-25, 2013.

GLUECK, N. Rivers in the desert: a history of the Negev. Nova York: Farrar, Straus \& Cudahy, 1959.

KAEFER, J.A. A Bíblia, a arqueologia e a bistória de Israel e Judá. Nova Coleção Bíblica. São Paulo: Paulus, 2015.

KLINGBEIL, G.A. Diálogo Universitário, vol. 14, n. 1, p. 17-19, 34, 2002.

MOOREY, P.R.S. A century of biblical archaeology. Louisville: John Knox Westminster Press, 1991.

OWEN, F. Suplemento arqueológico. In: Bíblia de Referência Thompson. São Paulo: Vida Nova, 2002.

PRICE, J.R. Arqueologia bíblica. São Paulo: CPAD, 2006, p.263.

RENFREW, C.; BAHN, P. Arqueologia: teorías, métodos y práctica. Madrid: Akal, 2007.

RODRIGUES, G.B.; FUNARI, P.P.A. Considerações sobre a trajetória inicial da arqueologia bíblica. Mosaico, vol. 2, n. 2, p. 100, jul./dez. 2009.

SHANKS, H. Para compreender os manuscritos do mar morto. Rio de Janeiro: Imago, 1992.

SOTELO, Daniel. Arqueologia bíblica. São Paulo: Novo Século, 2003.

The New York Times. Dr. Nelson Glueck Dead at 70, Archeologist and College Head. Feb. 14, 1971 , p. 75.

SOUSA, João Carlos Moreno de. Arqueologia: o que é isso? Disponível em https://arqueologiaeprehistoria.com/o-que-e-arqueologia/ 